REVIEW ARTICLE

\title{
The Emerging Role of Histone Demethylases in Renal Cell Carcinoma
}

\author{
Xiaoqiang Guo ${ }^{1,2,3}$, Qiaoxia Zhang ${ }^{1}$ \\ ${ }^{1}$ State Engineering Laboratory of Medical Key Technologies Application of Synthetic Biology, Key Laboratory of Medical Reprogramming \\ Technology, Shenzhen Second People's Hospital, The First Affiliated Hospital of Shenzhen University, Shenzhen, Guangdong, China; \\ ${ }^{2}$ Department of Urology, Shenzhen Second People's Hospital, The First Affiliated Hospital of Shenzhen University, Shenzhen, Guangdong, \\ China; ${ }^{3}$ Laboratory of Molecular Iron Metabolism, College of Life Science, Hebei Normal University, Shijiazhuang, Hebei, China
}

\begin{abstract}
Renal cell carcinoma (RCC), the most common kidney cancer, is responsible for more than 100,000 deaths per year worldwide. The molecular mechanism of RCC is poorly understood. Many studies have indicated that epigenetic changes such as DNA methylation, noncoding RNAs, and histone modifications are central to the pathogenesis of cancer. Histone demethylases (KDMs) play a central role in histone modifications. There is emerging evidence that KDMs such as KDM3A, KDM5C, KDM6A, and KDM6B play important roles in RCC. The available literature suggests that KDMs could promote RCC development and progression via hypoxia-mediated angiogenesis pathways. Small-molecule inhibitors of KDMs are being developed and used in preclinical studies; however, their clinical relevance is yet to be established. In this mini review, we summarize our current knowledge on the putative role of histone demethylases in RCC.
\end{abstract}

Keywords: histone demethylases; KDM3A; KDM5C; KDM6A; KDM6B; renal cell carcinoma

Received: 12 February 2017; Accepted after revision: 06 April 2017; Published: 03 May 2017.

Author for correspondence: Xiaoqiang Guo, Department of Urology, Shenzhen Second People's Hospital, The First Affiliated Hospital of Shenzhen University, Shenzhen 518035, Guangdong, China. Email: xiaoqiangguo123@163.com

How to cite: Guo X et al. The Emerging Role of Histone Demethylases in Renal Cell Carcinoma. J Kidney Cancer VHL 2017;4(2):1-5.

DOI: http://dx.doi.org/10.15586/jkcvhl.2017.56

Copyright: Guo X et al.

License: This open access article is licensed under Creative Commons Attribution 4.0 International (CC BY 4.0). http://creativecommons.org/ licenses/by/4.0

\section{Introduction}

Renal cell carcinoma (RCC) accounts for $2 \%-3 \%$ of all adult malignancies and causes more than 100,000 deaths per year worldwide (1). Radical or partial nephrectomy of the tumor at an early stage remains the mainstay of curative therapy (2). Metastases are present at the time of initial diagnosis in approximately one-third of patients, which are generally resistant to chemotherapy and radiation therapy (3). A better understanding of molecular mechanisms of RCC is necessary for improvement of treatment outcomes. Epigenetics refers to functionally relevant changes in the genome that affect the expression of specific genes without the involvement of changes in the DNA sequence (4). The common epigenetic events include DNA methylation, changes in noncoding RNAs and posttranslational modifications (PTMs) of histone. PTMs of histone involve the covalent modification of histone through acetylation, methylation, and phosphorylation (5). PTMs of histone regulate DNA replication, transcription, and 
repair of many biological processes (6). Histone methylation, a process by which methyl groups are transferred to lysine or arginine residues of histone, is a type of PTM of histone. Histone methylation influences many biological processes in the context of development and cellular responses (7). Abnormality of histone methylation can lead to various disorders including cancer (8). In this mini review, we summarize the emerging role of histone demethylases, key players in histone methylation, in RCC.

\section{Histone Demethylases and RCC}

In 2004, the first histone demethylase KDM1 was discovered, and in the earlier days histone methylation was thought to be irreversible $(9,10)$. In 2006, several jumonji C (JmjC)domain-containing demethylases were identified $(11,12)$, and subsequent studies showed that histone methylation is reversible. Histone demethylases play a key role in eukaryotic transcription (activation or repression) and other chromatindependent processes such as chromosome condensation and DNA damage (13). These demethylases have been implicated in the control of gene expression and cell fate decisions $(14,15)$. Many histone demethylases have been linked to human diseases (15-17), including RCC (Table 1).

\section{KDM3A}

KDM3A (also named as JMJD1A, JHDM2A) is an H3K 9 me1/2 demethylase of JmjC family and plays an essential role in spermatogenesis and adipogenesis $(13,14)$. KDM3A is also involved in other cellular processes such as cell cycle, embryonic and adult stem cell renewal, and differentiation of vascular smooth muscle (15). KDM3A has been implicated in the development and progression of several malignancies, including hepatocellular carcinoma and gastric cancer $(16,17)$. We and other researchers have reported that overexpression of $\mathrm{KDM} 3 \mathrm{~A}$ is associated with RCC development $(18,19)$. RCC samples from patients showed a higher expression of KDM3A when compared with normal noncancerous regions of the kidneys. Furthermore, KDM3A was highly expressed around blood vessels of RCC samples (18). KDM3A was also associated with an increase in hypoxia-inducible factor 1-alpha (HIF-1 $\alpha)$ (18). In vitro experiments with the RCC cell line 786-0 showed that KDM3A was higher in hypoxic conditions than in normoxic conditions. Taken together, these findings (18) suggest the potential role of KDM3A in RCC development and progression via hypoxia-mediated angiogenesis pathway.

\section{KDM5C}

KDM5C (also known as JARID1C) is an H3K4me1/2 demethylase that plays an important role in brain development and function. Mutations of KDMC5C can lead to $\mathrm{X}$-linked mental retardation (23). KDM5C abnormality was also associated with cancer development. For example, KDM5C was significantly upregulated in breast cancer tissues compared with paired normal breast tissues, and was positively correlated with metastasis (24). Inactivating mutations of KDM5C were identified in 101 clear cell RCC (ccRCC) cases using massive parallel sequencing technologies (20). Further studies in $132 \mathrm{ccRCC}$ patients showed that KDM5C was mutated in $4 \%$ of the cases (21).

\section{KDM6A and KDM6B}

KDM6A (also named as UTX) is an H3K27me2/3 demethylase, that is, essential for normal embryonic development and tissue-specific differentiation (25). Inactivating somatic mutations of KDM6A have been identified in RCC (26). Our results showed that expression of KDM6A is upregulated in RCC (22). KDM6B, also known as JMJD3, is another H3K27me2/3 demethylase that plays important roles in inflammatory response and senescence (27). We found that $\mathrm{KDM} 6 \mathrm{~B}$ is also overexpressed in $\mathrm{RCC}$, and maybe involved in oncogene-induced senescence (22). Thus, both KDM6A and KDM6B appear to have a proto-oncogenic role in $\mathrm{RCC}$.

\section{Possible Mechanisms of Histone Demethylases in RCC Development}

RCC is a hypoxia-related cancer because inactivating mutations of the tumor suppressor von Hippel-Lindau (VHL) gene are frequent in RCC than in other cancers. VHL is a ubiquitin ligase and its inactivation leads to increased protein stability of HIF1- $\alpha$ (28). HIF can change global patterns of histone modifications through transactivation of several histone demethylases $(29,30)$. Histone demethylases such as

Table 1. Histone demethylases implicated in RCC.

\begin{tabular}{|l|l|l|l|c|}
\hline Nomenclature & Official symbol & Sulbstrate & \multicolumn{1}{|c|}{ Function } & \multicolumn{1}{c|}{ References } \\
\hline KDM3A & JMJD1A & H3K9me1/2 & Metabolism, reproduction & $(18,19)$ \\
\hline KDM5C & JARID1C & H3K4me1/2 & Neural development & (22) \\
\hline KDM6A & UTX & H3K27me2/3 & Development \\
\hline KDM6B & JMJD3 & H3K27me2/3 & Inflammatory response, senescence & $(22)$
\end{tabular}

RCC, renal cell carcinoma. 
KDM3A, KDM3B, KDM4B, KDM5A, and KDM6B have been identified as HIF regulated demethylases (31). KDM3A has been established as a hypoxia-induced demethylase by several researchers (32-35). Upregulation of KDM3A mRNA and protein could be observed in RCC cell lines (786-0) exposed to hypoxia $(1 \% \mathrm{O})$ or iron scavengers (deferoxamine treatment). There is a hypoxia response element in the promoter region of the KDM3A gene, which can be bound by HIF-1 $(33,35)$. KDM6B was recently identified as a new hypoxiainducible histone demethylase $(36,37)$. The expressions of KDM6A and KDM6B are also regulated by nicotine and nickel $(38,39)$, which are thought to induce RCC $(40)$.

Histone demethylases can act as coactivators of certain nuclear factors including androgen receptor (AR), estrogen receptor, and HIF-1 $\alpha$. KDM3A is not only the coactivator of AR (13) but also the coactivator of HIF-1 $\alpha$ (41). KDM3A can further increase specific genes expression, such as GLUT3, adrenomedullin, c-Myc, FGF2, HGF, and ANG2 (41-43). VHL inactivation in $\mathrm{RCC}$ can decrease $\mathrm{H} 3 \mathrm{~K} 4 \mathrm{me} 3$ levels through $\mathrm{KDM} 5 \mathrm{C}$, which alters gene expression including IGFBP3 and GDF15 (44). In contrast, KDM5C inactivation can lead to genomic instability in RCC (45). These findings indicate that several histone demethylases can be induced under hypoxia which in turn regulate the expression of cancer-related genes, and trigger RCC development.

\section{Is There a Therapeutic Potential for KDM Inhibitors in RCC?}

Current targeted therapies for metastatic RCC mainly include mTOR inhibitors, VEGFA receptor tyrosine kinase inhibitors, and anti-VEGFA antibodies (46). However, their efficacies are limited, and there is a need to identify new targets. Histone demethylases are one of the promising targets (47). There is increasing interest in targeting KDMs with small molecules for therapeutic purposes (48). Several highthroughput screening strategies have been developed to screen for small-molecule inhibitors of KDMs (49). Many histone demethylase inhibitors are being developed and tested (50, 51), including GSK-J1/GSK-J4 (KDM6B inhibitor) and NSC 636819 (KDM4A/KDM4B inhibitor). Research has indicated that GSK-J4 has potent antitumor role both in cell lines and animal models of glioma by inhibiting the KDM6B activity and increasing H3K27 methylation (51). Although histone demethylase inhibitors have substantial medicinal potential for the treatment of cancer (52), the major challenge is that these inhibitors are either characterized by low specificity or that their target enzymes have low substrate specificity (53). Furthermore, to date, no conclusive data are available on the efficacy of histone demethylase inhibitors on RCC. However, given that several compounds such as vitamins $C$ and $D$ have regulatory effects on expression or activity of histone demethylases including KDM3A and KDM6B $(54,55)$, targeting histone demethylases appears to be a potential therapeutic option for RCC (56).

\section{Conclusion}

The past decade has witnessed tremendous improvements in the management of metastatic RCC through the introduction of many targeted therapies in clinical practice. Despite this, metastatic RCC still remains a difficult disease to treat. Better understanding of the molecular mechanisms that govern RCC development and progression will enable the development of novel compounds. There is emerging evidence that histone demethylases play a role in the development and progression of RCC, at least in part, via hypoxia-mediated angiogenesis pathway. This is particularly important given that hypoxia-induced angiogenesis pathway plays a crucial role in RCC progression, largely mediated by aberrations of the VHL gene. Furthermore, most of the targeted therapies inhibit the angiogenesis pathway. Thus, inhibition of histone demethylases, because of their perceived role in hypoxiamediated angiogenesis, is a promising field for further exploration. In addition, the role of currently available targeted therapies on histone demethylases is another area for future research.

\section{Conflict of interest}

The authors declare no potential conflicts of interest with respect to research, authorship, and/or publication of this article.

\section{Acknowledgments}

This review was funded by the Natural Science Foundation of Hebei Province (No. H2014205082), the National Natural Science Foundation (No 81270686) and the National High Technology Research and Development Program of China (863 Program) (No. 2014AA020607).

\section{References}

1. Siegel RL, Miller KD, Jemal A. Cancer statistics, 2015. CA Cancer J Clin. 2015;65(1):5-29. http://dx.doi.org/10.3322/caac.21254

2. Ficarra V, Schips L, Guille F, Li G, De La Taille A, Prayer Galetti T, et al. Multiinstitutional European validation of the 2002 TNM staging system in conventional and papillary localized renal cell carcinoma. Cancer. 2005;104(5):968-74. http:// dx.doi.org/10.1002/cncr.21254

3. Mohammed A, Shergill I, Little B. Management of metastatic renal cell carcinoma: Current trends. Expert Rev Mol Diagn. 2009;9(1):75-83. http://dx.doi.org/10.1586/14737159.9.1.75

4. Jones PA, Baylin SB. The fundamental role of epigenetic events in cancer. Nat Rev Genet. 2002;3(6):415-28. http://dx.doi.org/ 10.1038/nrg816

5. Tessarz P, Kouzarides T. Histone core modifications regulating nucleosome structure and dynamics. Nat Rev Mol Cell Biol. 2014;15(11):703-8. http://dx.doi.org/10.1038/nrm3890

6. Bannister AJ, Kouzarides T. Regulation of chromatin by histone modifications. Cell Res. 2011;21(3):381-95. http://dx.doi.org/10. 1038/cr.2011.22

7. Greer EL, Shi Y. Histone methylation: A dynamic mark in health, disease and inheritance. Nat Rev Genet. 2012;13(5): 343-57. http://dx.doi.org/10.1038/nrg3173

8. Black JC, Van Rechem C, Whetstine JR. Histone lysine methylation dynamics: Establishment, regulation, and biological impact. 
Mol Cell. 2012;48(4):491-507. http://dx.doi.org/10.1016/j.molcel. 2012.11.006

9. Pedersen MT, Helin K. Histone demethylases in development and disease. Trends Cell Biol. 2010;20(11):662-71. http://dx. doi.org/10.1016/j.tcb.2010.08.011

10. Shi Y, Lan F, Matson C, Mulligan P, Whetstine JR, Cole PA, et al. Histone demethylation mediated by the nuclear amine oxidase homolog LSD1. Cell. 2004;119(7):941-53. http://dx. doi.org/10.1016/j.cell.2004.12.012

11. Tsukada Y, Fang J, Erdjument-Bromage H, Warren ME, Borchers $\mathrm{CH}$, Tempst $\mathrm{P}$, et al. Histone demethylation by a family of JmjC domain-containing proteins. Nature. 2006;439(7078): 811-16. http://dx.doi.org/10.1038/nature04433

12. Dimitrova E, Turberfield AH, Klose RJ. Histone demethylases in chromatin biology and beyond. EMBO Rep. 2015;16(12): 1620-39. http://dx.doi.org/10.15252/embr.201541113

13. Okada Y, Scott G, Ray MK, Mishina Y, Zhang Y. Histone demethylase JHDM2A is critical for Tnp1 and Prm1 transcription and spermatogenesis. Nature. 2007;450(7166):119-23. http://dx.doi.org/10.1038/nature06236

14. Tateishi K, Okada Y, Kallin EM, Zhang Y. Role of Jhdm2a in regulating metabolic gene expression and obesity resistance. Nature. 2009;458(7239):757-61. http://dx.doi.org/10.1038/nature 07777

15. Kasioulis I, Syred HM, Tate P, Finch A, Shaw J, Seawright A, et al. $\mathrm{Kdm} 3$ a lysine demethylase is an Hsp90 client required for cytoskeletal rearrangements during spermatogenesis. Mol Biol Cell. 2014;25(8):1216-33. http://dx.doi.org/10.1091/mbc. E13-08-0471

16. Yamada D, Kobayashi S, Yamamoto H, Tomimaru Y, Noda T, Uemura M, et al. Role of the hypoxia-related gene, JMJD1A, in hepatocellular carcinoma: Clinical impact on recurrence after hepaticresection. Ann Surg Oncol. 2012;19 Suppl 3:S355-64. http://dx.doi.org/10.1245/s10434-011-1797-x

17. Yang H, Liu Z, Yuan C, Zhao Y, Wang L, Hu J, et al. Elevated JMJD1A is a novel predictor for prognosis and a potential therapeutic target for gastric cancer. Int J Clin Exp Pathol. 2015;8(9): 11092-9.

18. Guo X, Shi M, Sun L, Wang Y, Gui Y, Cai Z, et al. The expression of histone demethylase JMJD1A in renal cell carcinoma. Neoplasma. 2011;58(2):153-7. http://dx.doi.org/10.4149/neo_2011_ 02_153

19. Krieg AJ, Rankin EB, Chan D, Razorenova O, Fernandez S, Giaccia AJ. Regulation of the histone demethylase JMJD1A by hypoxia-inducible factor 1 alpha enhances hypoxic gene expression and tumor growth. Mol Cell Biol. 2010;30(1):344-53. http://dx.doi.org/10.1128/MCB.00444-09

20. Dalgliesh GL, Furge K, Greenman C, Chen L, Bignell G, Butler A, et al. Systematic sequencing of renal carcinoma reveals inactivation of histone modifying genes. Nature. 2010;463(7279): 360-3. http://dx.doi.org/10.1038/nature08672

21. Gossage L, Murtaza M, Slatter AF, Lichtenstein CP, Warren A, Haynes B, et al. Clinical and pathological impact of VHL, PBRM1, BAP1, SETD2, KDM6A, and JARID1c in clear cell renal cell carcinoma. Genes Chromosomes Cancer. 2014;53(1): 38-51. http://dx.doi.org/10.1002/gcc. 22116

22. Shen Y, Guo X, Wang Y, Qiu W, Chang Y, Zhang A, et al. Expression and significance of histone H3K27 demethylases in renal cell carcinoma. BMC Cancer. 2012;12:470. http://dx.doi. org/10.1186/1471-2407-12-470

23. Kramer JM, van Bokhoven H. Genetic and epigenetic defects in mental retardation. Int J Biochem Cell Biol. 2009;41(1):96-107. http://dx.doi.org/10.1016/j.biocel.2008.08.009
24. Wang Q, Wei J, Su P, Gao P. Histone demethylase JARID1C promotes breast cancer metastasis cells via down regulating BRMS1 expression. Biochem Biophys Res Commun. 2015; 464(2):659-66. http://dx.doi.org/10.1016/j.bbrc.2015.07.049

25. Van der Meulen J, Speleman F, Van Vlierberghe P. The H3K27me3 demethylase UTX in normal development and disease. Epigenetics. 2014;9(5):658-68. http://dx.doi.org/10.4161/ epi. 28298

26. van Haaften G, Dalgliesh GL, Davies H, Chen L, Bignell G, Greenman C, et al. Somatic mutations of the histone H3K27 demethylase gene UTX in human cancer. Nat Genet. 2009; 41(5):521-3. http://dx.doi.org/10.1038/ng.349

27. Swigut T, Wysocka J. H3K27 demethylases, at long last. Cell. 2007;131(1):29-32. http://dx.doi.org/10.1016/j.cell.2007.09.026

28. Baldewijns MM, van Vlodrop IJ, Vermeulen PB, Soetekouw PM, van Engeland M, de Bruïne AP. VHL and HIF signalling in renal cell carcinogenesis. J Pathol. 2010;221(2):125-38. http://dx. doi.org/10.1002/path.2689

29. Hancock RL, Dunne K, Walport LJ, Flashman E, Kawamura A. Epigenetic regulation by histone demethylases in hypoxia. Epigenomics. 2015;7(5):791-811. http://dx.doi.org/10.2217/epi.15.24

30. Xia X, Lemieux ME, Li W, Carroll JS, Brown M, Liu XS, et al. Integrative analysis of HIF binding and transactivation reveals its role in maintaining histone methylation homeostasis. Proc Natl Acad Sci USA. 2009;106(11):4260-5. http://dx.doi.org/ 10.1073/pnas.0810067106

31. Melvin A, Rocha S. Chromatin as an oxygen sensor and active player in the hypoxia response. Cell Signal. 2012;24(1):35-43. http://dx.doi.org/10.1016/j.cellsig.2011.08.019

32. Beyer S, Kristensen MM, Jensen KS, Johansen JV, Staller P. The histone demethylases JMJD1A and JMJD2B are transcriptional targets of hypoxia-inducible factor HIF. J Biol Chem. 2008;283(52):36542-52. http://dx.doi.org/10.1074/jbc. M804578200

33. Wellmann S, Bettkober M, Zelmer A, Seeger K, Faigle M, Eltzschig HK, et al. Hypoxia upregulates the histone demethylase JMJD1A via HIF-1. Biochem Biophys Res Commun. 2008;372(4):892-7. http://dx.doi.org/10.1016/j.bbrc.2008.05.150

34. Sar A, Ponjevic D, Nguyen M, Box AH, Demetrick DJ. Identification and characterization of demethylase JMJD1A as a gene upregulated in the human cellular response to hypoxia. Cell Tissue Res. 2009;337(2):223-34. http://dx.doi.org/10.1007/ s00441-009-0805-y

35. Pollard PJ, Loenarz C, Mole DR, McDonough MA, Gleadle JM, Schofield CJ, et al. Regulation of Jumonji-domain-containing histone demethylases by hypoxia-inducible factor (HIF)-1alpha. Biochem J. 2008;416(3):387-94. http://dx.doi.org/10.1042/BJ 20081238

36. Lee HY, Choi K, Oh H, Park YK, Park H. HIF-1-dependent induction of Jumonji domain-containing protein (JMJD) 3 under hypoxic conditions. Mol Cells. 2014;37(1):43-50. http:// dx.doi.org/10.14348/molcells.2014.2250

37. Guo X, Tian Z, Wang X, Pan S, Huang W, Shen Y, et al. Regulation of histone demethylase KDM6B by hypoxia-inducible factor-2 $\alpha$. Acta Biochim Biophys Sin (Shanghai). 2015;47(2): 106-13. http://dx.doi.org/10.1093/abbs/gmu122

38. Guo X, Li X, Wang Y, Tian Z, Duan X, Cai Z. Nicotine induces alteration of H3K27 demethylase UTX in kidney cancer cell. Hum Exp Toxicol. 2014;33(3):264-9. http://dx.doi.org/10.1177/ 0960327113499043

39. Guo X, Zhang Y, Zhang Q, Fa P, Gui Y, Gao G, et al. The regulatory role of nickel on $\mathrm{H} 3 \mathrm{~K} 27$ demethylase JMJD3 in kidney 
cancer cells. Toxicol Ind Health. 2016;32(7):1286-92. http://dx. doi.org/10.1177/0748233714552687

40. Lipworth L, Tarone RE, McLaughlin JK. The epidemiology of renal cell carcinoma. J Urol. 2006;176(6 Pt 1):2353-8. http://dx. doi.org/10.1016/j.juro.2006.07.130

41. Mimura I, Nangaku M, Kanki Y, Tsutsumi S, Inoue T, Kohro $\mathrm{T}$, et al. Dynamic change of chromatin conformation in response to hypoxia enhances the expression of GLUT3 (SLC2A3) by cooperative interaction of hypoxia-inducible factor 1 and KDM3A. Mol Cell Biol. 2012;32(15):3018-32. http://dx.doi. org/10.1128/MCB.06643-11

42. Park SJ, Kim JG, Son TG, Yi JM, Kim ND, Yang K, et al. The histone demethylase JMJD1A regulates adrenomedullinmediated cell proliferation in hepatocellular carcinoma under hypoxia. Biochem Biophys Res Commun. 2013;434(4):722-7. http://dx.doi.org/10.1016/j.bbrc.2013.03.091

43. Osawa T, Tsuchida R, Muramatsu M, Shimamura T, Wang F, Suehiro J, et al. Inhibition of histone demethylase JMJD1A improves anti-angiogenic therapy and reduces tumor-associated macrophages. Cancer Res. 2013;73(10):3019-28. http://dx.doi. org/10.1158/0008-5472.CAN-12-3231

44. Niu X, Zhang T, Liao L, Zhou L, Lindner DJ, Zhou M, et al. The von Hippel-Lindau tumor suppressor protein regulates gene expression and tumor growth through histone demethylase JARID1C. Oncogene. 2012;31(6):776-86. http://dx.doi.org/ 10.1038/onc.2011.266

45. Rondinelli B, Rosano D, Antonini E, Frenquelli M, Montanini L, Huang D, et al. Histone demethylase JARID1C inactivation triggers genomic instability in sporadic renal cancer. J Clin Invest. 2015;125(12):4625-37. http://dx.doi.org/10.1172/JCI81040

46. Su D, Stamatakis L, Singer EA, Srinivasan R. Renal cell carcinoma: Molecular biology and targeted therapy. Curr Opin Oncol. 2014;26(3):321-7. http://dx.doi.org/10.1097/CCO. 0000000000000069

47. Natoli G, Testa G, De Santa F. The future therapeutic potential of histone demethylases: A critical analysis. Curr Opin Drug Discov Devel. 2009;12(5):607-15.
48. McAllister TE, England KS, Hopkinson RJ, Brennan PE, Kawamura A, Schofield CJ. Recent progress in histone demethylase inhibitors. J Med Chem. 2016;59(4):1308-29. http://dx.doi. org/10.1021/acs.jmedchem.5b01758

49. Gale M, Yan Q. High-throughput screening to identify inhibitors of lysine demethylases. Epigenomics. 2015;7(1):57-65. http://dx. doi.org/10.2217/epi.14.63

50. Rotili D, Tomassi S, Conte M, Benedetti R, Tortorici M, Ciossani G, et al. Pan-histone demethylase inhibitors simultaneously targeting Jumonji $\mathrm{C}$ and lysine-specific demethylases display high anticancer activities. J Med Chem. 2014;57(1): 42-55. http://dx.doi.org/10.1021/jm4012802

51. Hashizume R, Andor N, Ihara Y, Lerner R, Gan H, Chen X, et al. Pharmacologic inhibition of histone demethylation as a therapy for pediatric brainstem glioma. Nat Med. 2014;20(12): 1394-6. http://dx.oi.org/10.1038/nm.3716

52. Thinnes CC, England KS, Kawamura A, Chowdhury R, Schofield CJ, Hopkinson RJ. Targeting histone lysine demethylases Progress, challenges, and the future. Biochim Biophys Acta. 2014;1839(12):1416-32. http://dx.doi.org/10.1016/j.bbagrm.2014. 05.009

53. Mund C, Lyko F. Epigenetic cancer therapy: Proof of concept and remaining challenges. Bioessays. 2010;32(11):949-57. http:/ dx.doi.org/10.1002/bies.201000061

54. Guo X, Lu J, Wang Y, Gui Y, Duan X, Cai Z. Ascorbate antagonizes nickel ion to regulate JMJD1A expression in kidney cancer cells. Acta Biochim Biophys Sin (Shanghai). 2012;44(4): 330-8. http://dx.doi.org/10.1093/abbs/gms004

55. Pereira F, Barbáchano A, Singh PK, Campbell MJ, Muñoz A Larriba MJ. Vitamin D has wide regulatory effects on histone demethylase genes. Cell Cycle. 2012;11(6):1081-9. http://dx.doi. org/10.4161/cc.11.6.19508

56. Larkin J, Goh XY, Vetter M, Pickering L, Swanton C. Epigenetic regulation in RCC: Opportunities for therapeutic intervention? Nat Rev Urol. 2012;9(3):147-55. http://dx.doi.org/10.1038/ nrurol.2011.236 